\title{
ACCELERTED TESTING OF DETERIORATED CONCRETE STRUCTURES DUE TO CARBONATION
}

\author{
T. Chandrasekaraiah ${ }^{1}$, H. Anantharam ${ }^{2}$, Krishnamurthy $M^{3}$, K. V. Manjunath ${ }^{4}$, M.N. Hegde ${ }^{5}$ \\ ${ }^{1}$ Faculty, Department of Civil Engineering, Dr. Ambedkar Institute of Technology, Bangalore-560 056 \\ ${ }^{2}$ Faculty, Department of Civil Engineering, Dr. Ambedkar Institute of Technology, Bangalore-560 056 \\ ${ }^{3}$ Faculty, Department of Civil Engineering, Dr. Ambedkar Institute of Technology, Bangalore-560 056 \\ ${ }^{4}$ Faculty, Department of Civil Engineering, Dr. Ambedkar Institute of Technology, Bangalore-560 056 \\ ${ }^{5}$ Faculty, Department of Civil Engineering, Dr. Ambedkar Institute of Technology, Bangalore-560 056
}

\begin{abstract}
Normally in reinforced concrete structures, the reinforcing steel is well protected against corrosion by concrete. The reinforcing steel remains passive under high alkalinity. However, the highly desirable durability requirement is not always achieved in practice due to various environmental factors. Corrosion of reinforcement in concrete is a common cause of deterioration in many RC structures. Two main cause of corrosion of reinforcement in concrete are: Carbonation and presence of Chloride ions. Carbonation is the result of the chemical reaction between carbon dioxide gases in the atmosphere and alkaline hydroxides in the concrete. The rate of carbonation depends on the thickness of the concrete cover and also on its quality in terms of the mixing ratios that achieve the highest quality. The relative humidity and temperature mainly affects the carbonation of concrete. Permeability, nature and intensity of cracks, and cover thickness will influence the initiation and sustenance of reinforcement corrosion. The expansion of the corroding steel causes surface cracking and subsequent spalling of the cover concrete.
\end{abstract}

This paper presents the experimental results of the work carried out on carbonation of concrete M30 and M40 grades with different $\mathrm{CO}_{2}$ concentration and exposure period.

\section{INTRODUCTION}

Deterioration of RC Structures is directly related to deterioration of materials i.e. concrete and steel in its members. Degradation of concrete is related to its durability aspect and that of reinforcing steel to its corrosion. For the condition assessment of RC structure, one has to have a thorough knowledge of the various causes of deterioration and their effects on materials. It is necessary to separate the causes of degradation of concrete and steel though they are occurring simultaneously in structural members.

The Durability is a major concern for concrete structures exposed to aggressive environments. Carbonation is one of the major factors to cause structure deterioration. Carbonation is the reaction of the hydration products dissolved in the pore water with the carbon dioxide in the air which reduces the $\mathrm{pH}$ of concrete pore solution. Carbonation reduces $\mathrm{pH}$ value and destroys the passive film around the steel, but it seems to densify concrete surface and reduce chloride ion permeability, reduce surface porosity and hence sorptivity in concrete. Carbonation could have both positive and negative effects on concrete durability. The presence of even a small amount of chloride in carbonated concrete enhances the corrosion rate resulted from carbonation of concrete.
The study of the durability of concrete structures needs a multidisciplinary approach based on the physics and chemistry of the materials. In particular the durability depends both on the ability of concrete to resist the penetration of aggressive substances from the environment, and on its ability to protect embedded steel reinforcement. The transport of aggressive species may follow different mechanisms, depending on the pore structure of the concrete, the exposure conditions and characteristics of the diffusing substances. The penetration of carbon dioxide or oxygen, as well as of many other gaseous substances, may occur only if the pores of concrete are almost dry, while the diffusion of chloride or sulphate ions takes place only in water. Therefore all these mechanisms should be studied together with evolution of moisture content inside the concrete. One of the processes which takes place in the pores of concrete and which may limit the service life of reinforced concrete structures is the carbonation of material, i.e., the chemical process denoting the reaction of calcium hydroxide with carbon dioxide resulting in the formation of calcium carbonate and water. The main consequence of carbonation is the drop of the $\mathrm{pH}$ value of the pore solution of concrete from the standard values between 12.5 and 13.5 , to a value of about 8.3 in the fully carbonated zones, so that the passive layer that usually covers and protects the reinforcing steel against corrosion becomes no longer stable, Anna et al, (1993). The basic factor influencing carbonation is the diffusivity of the 
hardened cement paste. Carbonation rate is controlled by the ingress of $\mathrm{CO}_{2}$ into concrete pore system by diffusion with a concentration gradient of $\mathrm{CO}_{2}$ acting as the driving force. Factors affecting diffusion rate include the type and amount of cement, porosity of the material, time of curing, type and quantity of pozzolanic additions. Moreover, several mechanical properties of concrete such as compressive strength, surface hardness, and resistance to aggressive agents may change due to carbonation.

Corrosion of steel bars embedded in concrete is a worldwide problem that affects numerous Reinforced Concrete (RC) structures. Theoretical models have also been developed and calibrated with experimental results to predict the behaviour of concrete structures with corroding steel bars as well as their service lives. The corrosion process occurs under sustained load.

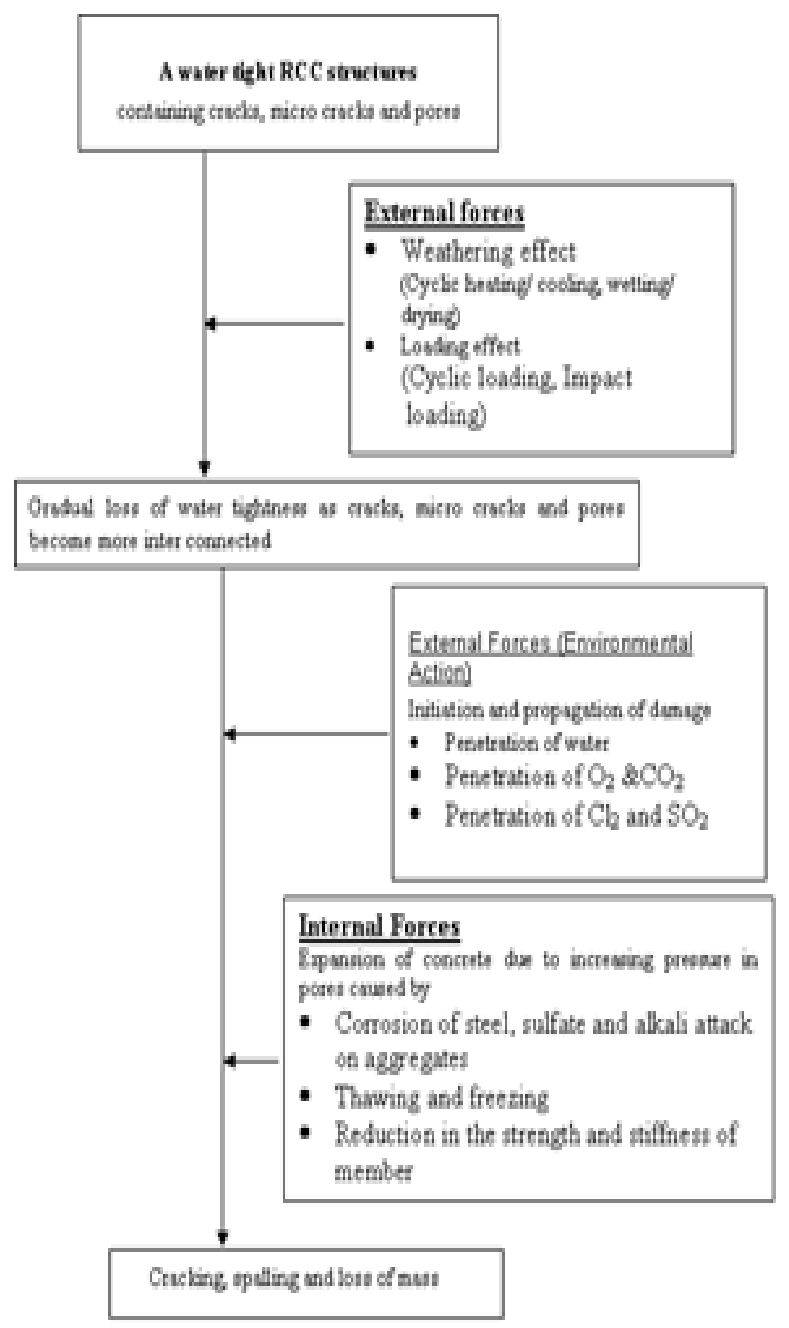

Fig. 1. Concrete and Steel degadation model
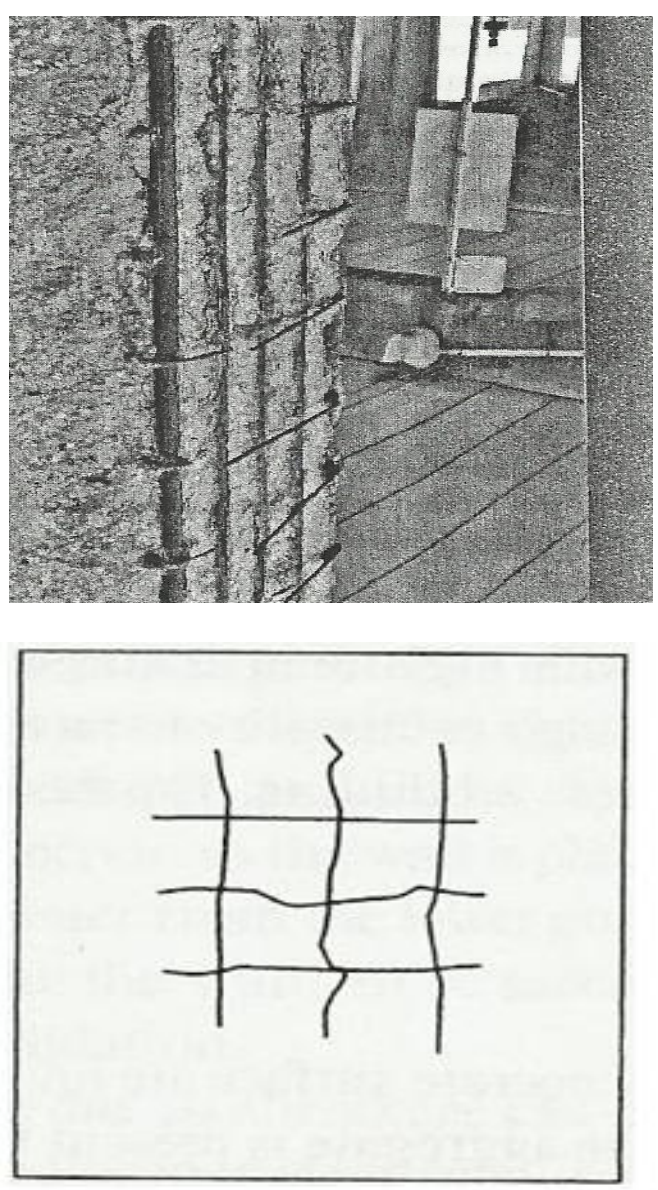

\section{Cracks Due to Steel Corrosion (Cracks parallel to steel bars)}
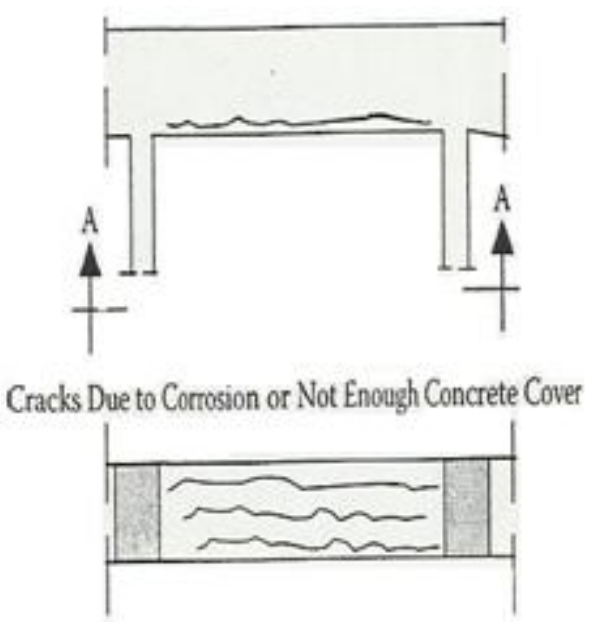

\section{Cracks Paralle to Main Steel in Case of Corrosion}

Fig 2 Corrosion of reinforcement in concrete (Source: Mohamed A. and El-Reedy, 2008) 


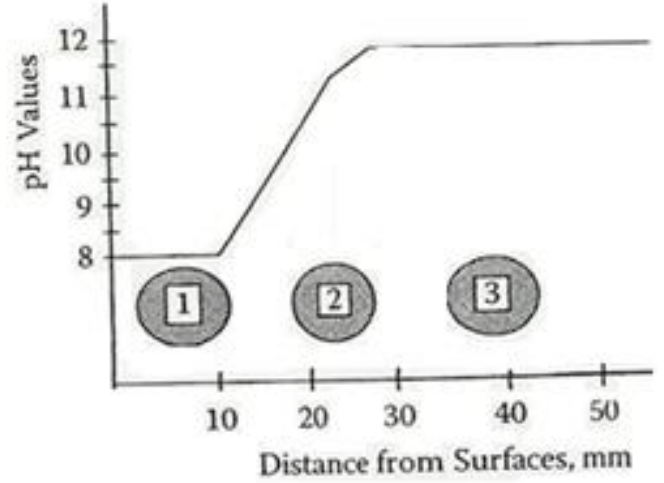

Fig 3 Relation between carbonation depth and level of $\mathrm{pH}$ values

(Source: Mohamed A. and El-Reedy, 2008)

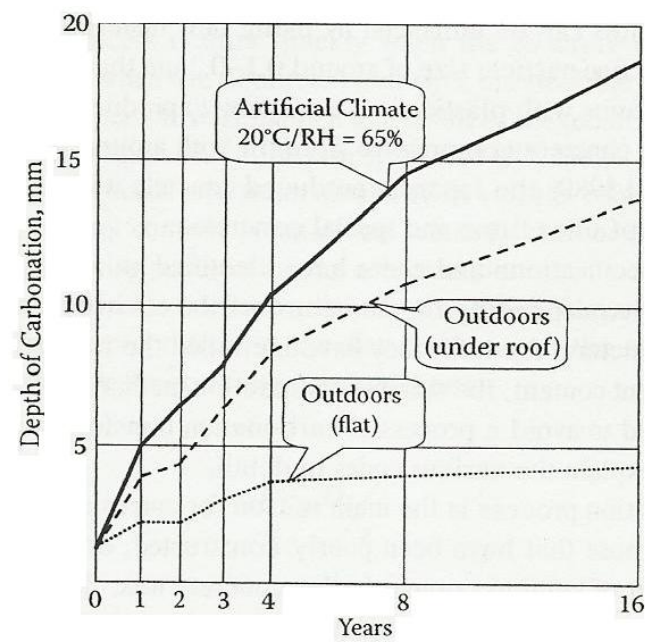

Fig 4 Effect of climatic conditions on the rate of carbonation

The mechanism of corrosion, effects of corrosion on concrete structures, measure to control corrosion, and effectiveness of repair and strengthening of corroded structures Soÿlev and Richardson, (2008). Theoretical models have also been developed and calibrated with experimental results to predict the behaviour of concrete structures with corroding steel bars as well as their service lives (Vidal et al, 2004, Li et al, 2006). Tarek Mohammed et al (1999) studied the orientation of steel bars (main steel and stirrups) in concrete during corrosion process. Orientation of steel bars has significant influence on macrocell and microcell corrosion of steel bars in concrete. It was observed that deformed bars corroded more than the plain bar. Formation of gaps under horizontal steels causes significant corrosion. Water cement ratio has a significant influence on corrosion of steel in concrete. Goitseone Malumbela et al 2009 reviewed previous studies carried out to investigate the effects of simultaneous load and steel corrosion, on the rates of corrosion and behaviour of RC structures. Corrosion under load was found to significantly increase deflection of specimens. There was no gain in stiffness during corrosion process under service load, which is often observed at early carrion stages on structures corroded in the absence of a sustained load (Soÿlev and Richardson, 2008; Li et al, 2006).

In the present study, concrete cube specimens are exposed to carbon dioxide in the carbonation chamber. The effect on compressive strength of concrete, $\mathrm{CO}_{2}$ concentration, curing periods, and duration of carbonation of concrete have been studied and reported.

\section{CARBONATION PROCESS}

Carbonation is a neutralizing procedure in which gases such as carbon dioxide $\left(\mathrm{CO}_{2}\right)$ in the atmosphere react with calcium hydroxide $\left(\mathrm{Ca}(\mathrm{OH})_{2}\right)$ dissolved in the concrete pore water, producing calcium carbonate $\left(\mathrm{CaCO}_{3}\right)$ and water $\left(\mathrm{H}_{2} \mathrm{O}\right)$. In addition hydrated calcium silicate $(\mathrm{CSH})$, unhydrated tricalcium silicate $\left(\mathrm{C}_{3} \mathrm{~S}\right)$ and bi-calcium silicate $\left(\mathrm{C}_{3} \mathrm{~S}\right)$ consume carbon dioxide as well. Carbonation changes the chemical composition and the microstructure of the concrete, thereby obviously affecting its chemical and mechanical properties. Carbonation is a very complex physical-chemical procedure where carbon dioxide penetrates, diffuses and reacts from surface to inside the concrete. The primary reactions are;

$$
\begin{aligned}
& \mathrm{CO}_{2}+\mathrm{H}_{2} \mathrm{O} \longrightarrow \mathrm{H}_{2} \mathrm{CO}_{3} \\
& \mathrm{Ca}(\mathrm{OH})_{2}+\mathrm{H}_{2} \mathrm{CO}_{3} \longrightarrow \mathrm{CaCO}_{3}+2 \mathrm{H}_{2} \mathrm{O} \\
& 3 \mathrm{CaO} .2 \mathrm{SiO}_{2} \cdot 3 \mathrm{H}_{2} \mathrm{O}+3 \mathrm{H}_{2} \mathrm{CO}_{3} \longrightarrow 3 \mathrm{CaCO}_{3} \cdot 2 \mathrm{SiO}_{2} \cdot 3 \mathrm{H}_{2} \mathrm{O}+3 \mathrm{H}_{2} \mathrm{O} \\
& 3 \mathrm{CaO} \cdot \mathrm{SiO}_{2}+3 \mathrm{H}_{2} \mathrm{CO}_{3} \longrightarrow 3 \mathrm{CaCO}_{3}+\mathrm{SiO}_{2} \cdot 3 \mathrm{H}_{2} \mathrm{O}
\end{aligned}
$$

In the study of carbonation process, the relative humidity seems to be very important. The maximum carbonation velocity has been observed at the relative humidity level of $50 \%$. At higher relative humidity levels, the samples seem to lose some compressive strength due to exposure to normal $\mathrm{CO}_{2}$ concentrations.

\section{EXPERIMENTAL PROGRAMME}

The two grades of concrete M30 and M40 were designed and cubes were cast. The test specimens were pond cured for 7, 14 and 28 days. After 28 days of curing, the concrete cubes were exposed to carbon dioxide of three intensities $(30 \%, 60 \%$, and $90 \%$ ) in the carbonation chamber for different periods of 24 , 48 and 72 hours. The intensity of carbon dioxide in the carbonation chamber is monitored at regular interval of 1 hour.

The strength of concrete cubes and porosity of concrete are evaluated for two grades of concrete M30 with water-cement ratio of 0.40 and M40 with water-cement ratio of 0.30 . The specimens were cured and carbonized using accelerated carbonation. Different period of curing and carbonation are 
adopted and tested. The depth of carbonation of concrete is established using core samples removed from carbonated concrete cubes. Non-destructive testing such as ultrasonic pulse velocity and rebound hammer tests have been carried out for finding the quality and strength of concrete. The effect on compressive strength of concrete, cement content, and curing period on carbonation and cover thickness and intensity of carbon dioxide on corrosion of reinforcement embedded in concrete have been studied.

\subsection{Porosity of Concrete}

The concrete porosity is one of the major factors affecting the durability of concrete. The porosity depends on the proportions of the ingredients and the construction practices. The porosity of concrete is established by knowing the dry weight of concrete cubes and wet weight of concrete cube i.e. the cubes immersed in water for twenty-four hours. The difference in dry weight and wet weight gives the weight of water penetrated into the concrete and the pores available in the concrete.

\subsection{Carbonation of Concrete}

The concrete cube specimens were exposed to carbon dioxide in the carbonation chamber for different durations with varying intensity of carbon dioxide. The intensity of carbon dioxide in the carbonation chamber is monitored using gas analyzer at regular interval. Figures $5 \& 6$ depict the carbonation chamber and staging arrangements for housing specimens. A continuous supply of carbon dioxide gas to the chamber was maintained throughout the investigations by burning rice husk ash and saw dust. Concrete cubes are exposed to carbon dioxide for known duration in the carbonation chamber.

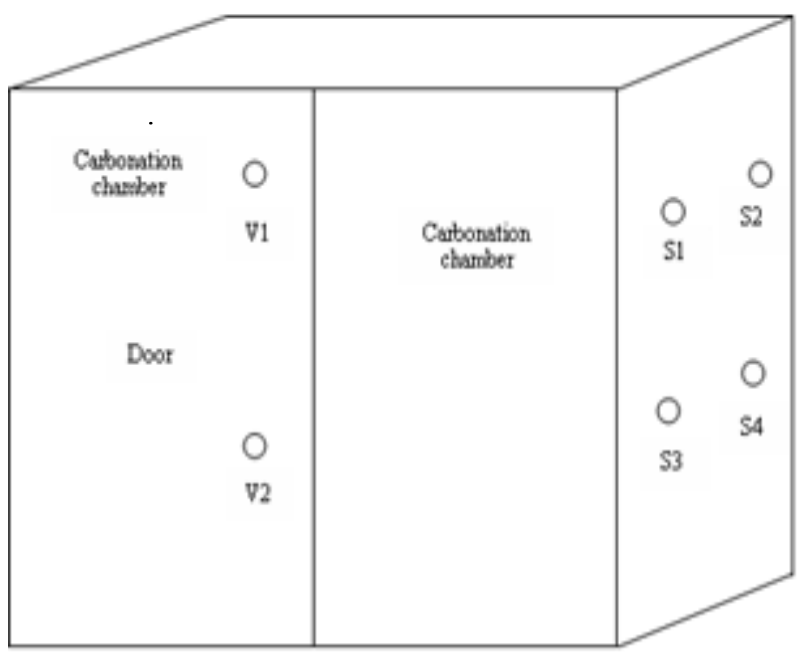

$(81,82,83$ and $\$ 4=$ Slits)

Fig 5 Elevation of Carbonation Chamber

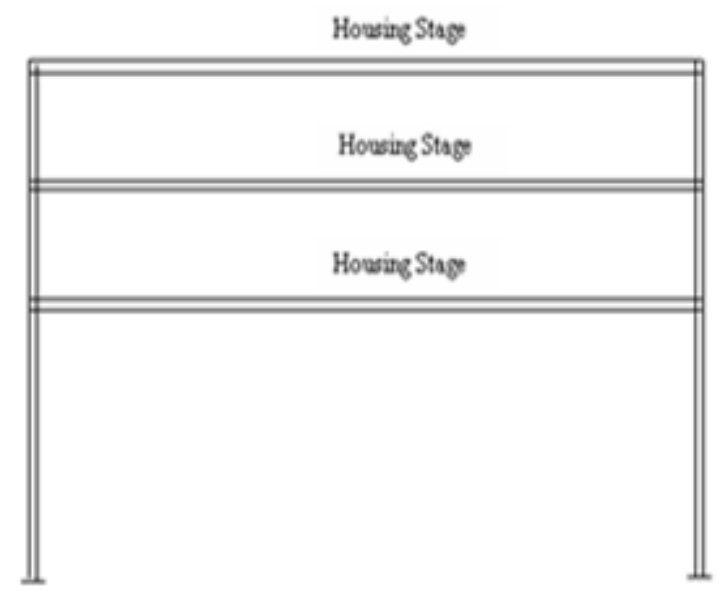

Fig 6 Elevation of staging for housing specimens in Carbonation Chamber

The depth of carbonation is established by removing the cores from the carbonated concrete cubes at the center of the specimen. The phenolphthalein solution is applied to a fresh fracture surface of concrete, the carbonated part of the concrete is found to be colourless showing $\mathrm{pH}$ value to be less than 8.6. On the other hand the uncarbonated concrete shows the pink colours of the phenolphthalein, the $\mathrm{pH}$ value is above 8.6. The depth of carbonation is measured from the surface of the core sample.

\section{RESULTS AND DISCUSSIONS}

The strength of concrete cubes is established using UPV tests and crushing cubes under compressive load. The variation of carbonation with respect to different parameter is discussed here. The depth of carbonation is established by the application of phenolphthalein solution on the core samples removed from the carbonated specimens. The carbonated surface becomes colourless after the application of phenolphthalein and uncarbonated surface is pink in colour. The temperature largely affects diffusion of gases and water; in the present investigation laboratory temperature of $27^{\circ} \mathrm{C}$ is considered and kept constant. The effects of water-cement ratio, curing periods, compressive strength of concrete, porosity of concrete, intensity of carbon dioxide, and duration of carbonation on carbonation of concrete are studied.

The amount of $\mathrm{CO}_{2}$ present in the atmosphere is of the order $0.03 \%$. The level of $\mathrm{CO}_{2}$ in the industrial areas and urban area are higher due to release of carbon dioxide from the industries and the exhaust gases from the locomotives. The carbon dioxide into the carbonation chamber of size $6^{\prime} \times 6^{\prime} \times 6^{\prime}$ is supplied by burning rice husk ash and other waste materials. The intensity of carbon dioxide in the carbonation chamber by volume is measured with the gas analyzer. The intensity of carbon dioxide $30 \%, 60 \%$ and $90 \%$ is used in the present 
investigation. The depth of carbonation increases with increase in $\mathrm{CO}_{2}$ content.

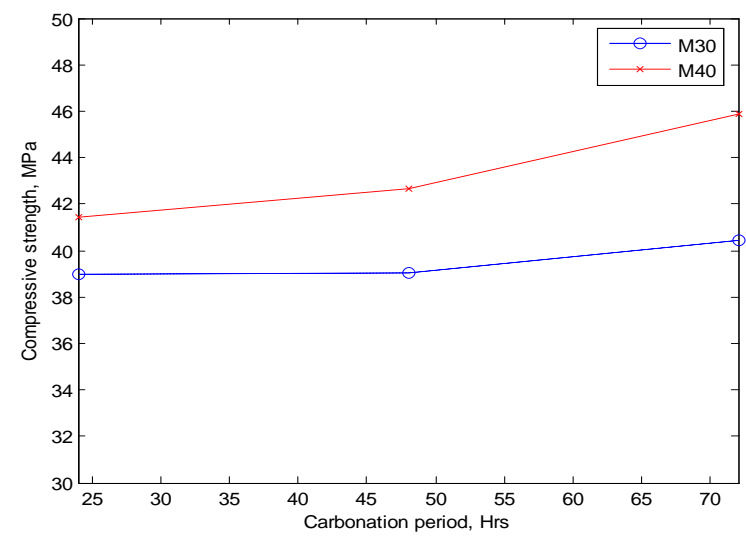

Fig 7 Compressive strength versus carbonation period at 28 days with $30 \% \mathrm{CO}_{2}$ concentration

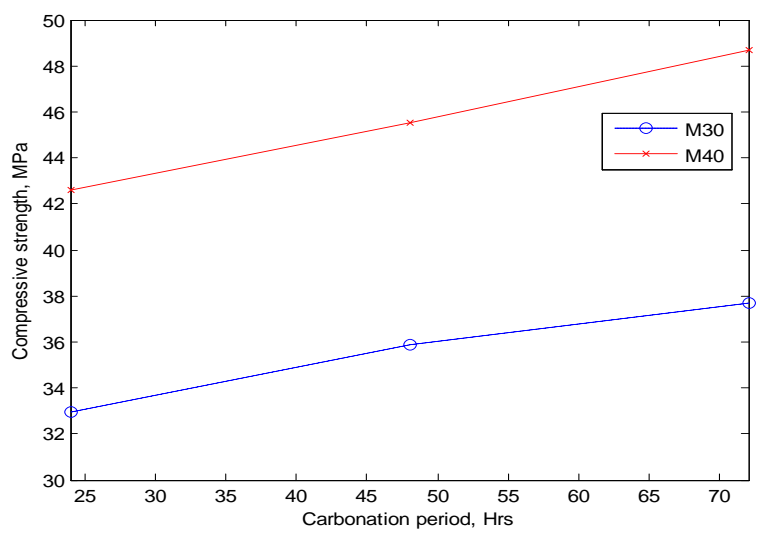

Fig 8 Compressive strength versus carbonation period at 28 days with $60 \% \mathrm{CO}_{2}$ concentration

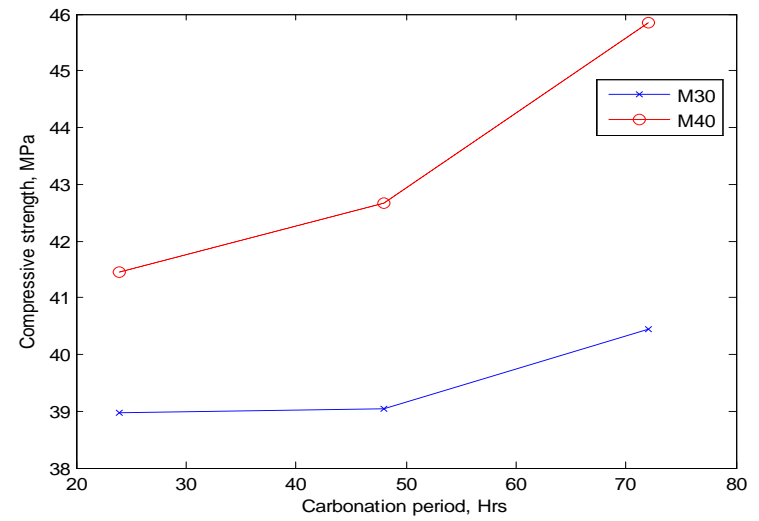

Fig 9 Compressive strength versus carbonation period at 28 days with $90 \% \mathrm{CO}_{2}$ concentration

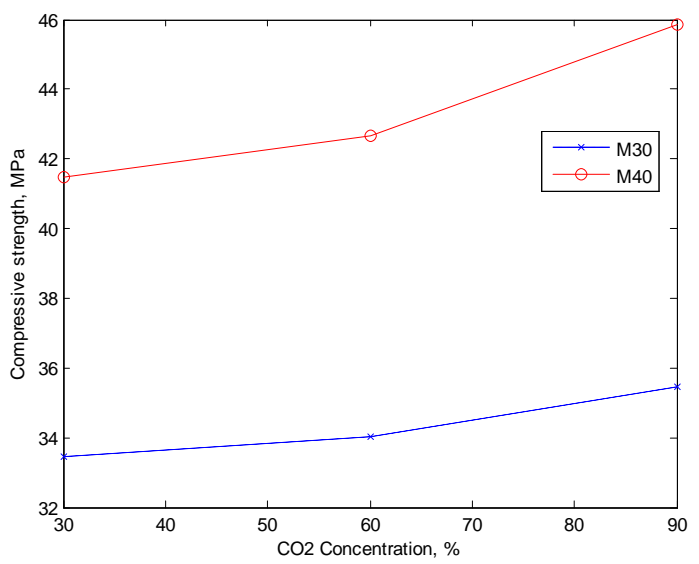

Fig 10 Compressive strength versus with $\mathrm{CO} 2$ concentration for $24 \mathrm{hrs}$ carbonation period

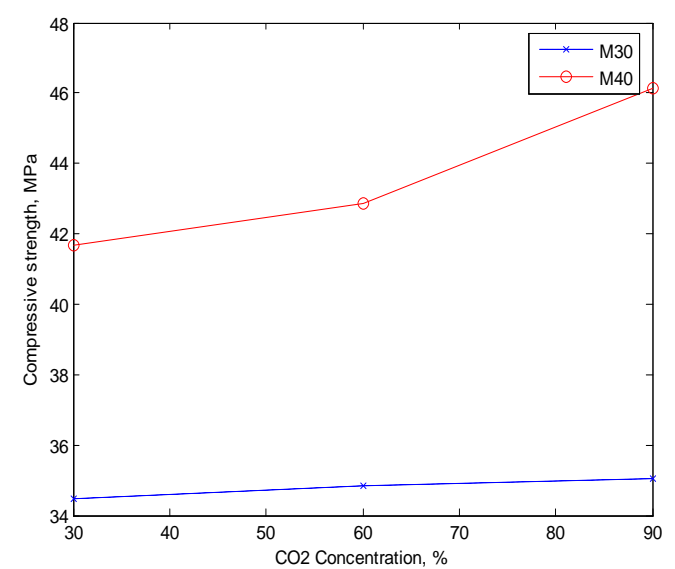

Fig 11 Compressive strength versus with $\mathrm{CO}_{2}$ concentration for $48 \mathrm{hrs}$ carbonation period

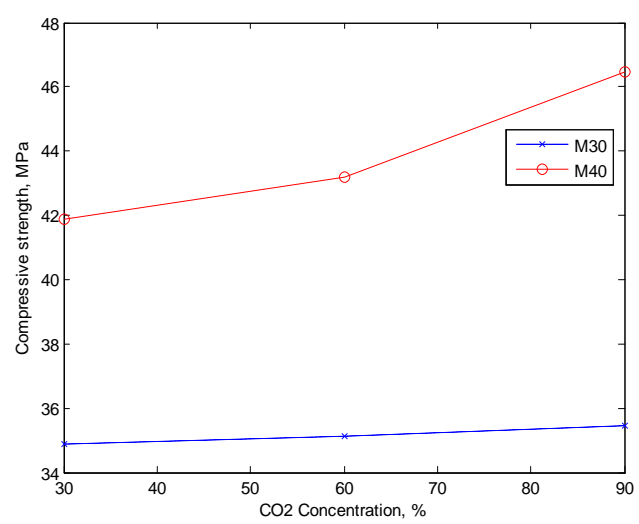

Fig 12 Compressive strength versus with $\mathrm{CO}_{2}$ concentration for $72 \mathrm{hrs}$ carbonation period 
Figs. 7 to 12 respectively represent the variation of compressive strength of concrete with intensities of carbon dioxide $30 \%, 60 \%$ and $90 \%$ for M30 and M40 concretes with exposure time 24, 48 and $72 \mathrm{hrs}$. Figs. 7 to 9 show the increase in compressive strength with the increase in $\mathrm{CO}_{2}$ content. Figs. 10 to 12 , show the increase in compressive strength with exposure duration.

The concrete specimens are carbonated in the carbonation chamber and durations of carbonation 24, 48 and $72 \mathrm{hrs}$ are adopted in the present investigation. It is observed that the depth of carbonation increased. It is also noticed that depth of carbonation increases with increase in duration of carbonation. The depth of carbonation depends on the grade of concrete and curing period. The depth of carbonation is more for M30 concrete when compared to M40 concrete. The compressive strength of carbonized cubes is more than the noncarbonised cubes which indicates that carbonation will affect the strength of concrete.

\section{CONCLUSIONS}

The following conclusions are deduced from the experimental results:

(i) The carbonation depth increases with an increase in exposure time and higher $\mathrm{CO}_{2}$ concentration results in higher carbonation depth for all mixtures.

(ii) The compressive strength of concrete increases with amount and duration of carbonation.

(iii) The compressive strength and splitting tensile strength of carbonated concrete at the age of 28 days are slightly higher than those of concrete without carbonation.

(iv) The electrical resistivity of concrete increases with an increase in exposure time and the amount of charge passed significantly decreases with an increase in carbonation depth. However, carbonation of concrete enhances the rate of corrosion of reinforcement from the electrochemical corrosion test results.

\section{ACKNOWLEDGEMENTS}

All India Council for Technical Education (AICTE), New Delhi, (File No. 8021/RID/NPROJ/ TAP-71/2002-03) provided financial support to this research. We are grateful for the financial support from AICTE, New Delhi and logistic support from Dr. Ambedkar Institute of Technology, Bangalore-560056.

\section{REFERENCES}

[1] Anna V. Saetta, Bernhard A, Schrefler and Renato V. Vitaliani, (1993), "The carbonation of Concrete and the mechanism of moisture, heat and carbon dioxide flow through porous materials", Cement and Concrete Research, Vol. 23: pp. 761-772.
[2] Cairns J, Dut Y, and Law D, (2008), "Structural performance of corrosion-damaged concrete beams", Magazine of Concrete Research, Vol. 60(5): pp. 359370 .

[3] Gěraldine Villain and Mickaël Thiery, (2005), "Impact of carbonation on microstructure and transport properties of concrete", 10DBMC Inter. Conf. on Durability of Building Mat. And Comp., Lyon, France.

[4] Goitseone Malumbela, Mark Alexander, Pilate Moyo, (2009), "Steel corrosion on RC structures under sustained service loads - A critical review", Engineering Structures, Vol. 31: pp. 2518-2525.

[5] Jack M. Chi, Ran Huang, and Yang, CC, (2002), "Effects of carbonation on mechanical properties and durability of concrete using accelerated testing method", Jl of Marine Sci. and Tech, Vol. 10(1): pp. 14-20.

[6] Jianzhuang Xiao, Jie Li, Bolong Zhu, and Ziyan Fan, (2002), "Experimental study on strength and ductility of carbonated concrete elements", Construction and Building Materials, Vol. 16: pp. 187-192.

[7] Jones, MR, Dhir RK, Newlands, MD and Abbas, AMO, (2000), "A study of the CEN test method for measurement of the carbonation depth of hardened concrete", Materials and Struct., Vol. 33: pp. 135-142.

[8] Li C, Melchers RE, and Zheng, J (2006), "Analytical model for corrosion induced crack width in reinforced concrete structures", ACI Structural Journal, Vol. 103: pp. 479-487.

[9] Li C, Zheng, J Lawanwisut W, and Melchers RE, (2007). "Concrete Delamination caused by steel reinforcement corrosion", Journal of Materials of Civil Engg. Vol. 19: pp. 591-600.

[10] Mohamed A. and El-Reedy, (2008), "SteelReinforced Concrete Structures-Assessment and Repair of Corrosion", CRC Press, Taylor and Francis Group, NY.

[11] Montemor M.F, Simões, AMP, Ferreira, MGS, (2003), "Chloride induced corrosion on reinforcing steel: from the fundamentals to the monitoring techniques", Cement and Concrete Comp., Vol. 23: pp. 491-502.

[12] Paulo Roberto Do Lago Helene and Pedro CastroBorges, (2009), "A novel method to predict concrete carbonation”, Concreto Y Cemento, Vol. 1(1): pp. 2535 .

[13] Soÿlev TA, and Richardson MG, (2008), "Corrosion inhibitors for steel in concrete: State-of-the-art report", Construction and Building Materials. Vol. 22: pp. 609-622.

[14] Tarek U. Mohammed, Nobuuaki Ostuki, and Makoto Hisada, (1999). "Corrosion of Steel bars with respect to Orientation in Concrete", ACI Materials Journal, 96,154-166. 
[15] Vidal T, Castel A, and Francis R, (2004), “Analyzing crack width to predict corrosion in reinforced concrete", Cement Concrete Research, Vol. 34: pp. 165-174. 